\title{
Características de uma ferramenta CAD voltada a uma abordagem integrada do processo de projeto em arquitetura
}

\author{
Aristóteles L. M. Cordeiro, M.Sc. \\ Programa de Pós-graduação em Engenharia de Produção \\ Centro de Tecnologia \\ Universidade Federal da Paraíba - UFPB \\ cordeiro@ openline.com.br \\ Francisco Soares Másculo, Ph.D. \\ Programa de Pós-graduação em Engenharia de Produção \\ Centro de Tecnologia \\ Universidade Federal da Paraíba - UFPB \\ $\underline{\text { masculo@producao.ct.ufpb.br }}$
}

Uma das tendências mais recentes no mercado de programas CAD, Computer Aided Design, é a crescente importância dos programas direcionados para apoiar um conjunto de tarefas de uma determinada profissão ou atividade, chamados de programas CAD dedicados, profissionais ou específicos. Este tipo de programa abandona definitivamente a metáfora de "prancheta eletrônica" utilizada não só para caracterizar os programas CAD como também para determinar a lógica de suas interfaces. Os programas que eram orientados ao desenho passam a ser orientados ao objeto, voltados para a construção não-ambígua de um modelo do que está sendo concebido. Este artigo levanta preliminarmente quais as características e/ou recursos desejáveis em um programa CAD voltado para o projeto de arquitetura e quais os obstáculos para a sua implementação operacional.

Palavras-chave: CAD; projeto de arquitetura; modelos de edificações.

One of the most recent trends in the CAD, Computer Aided Design, market is the growing importance of the so-called dedicated CAD, which is a CAD software designed to support a specific set of discipline or professional tasks. This new kind of CAD software left apart the "drawing board" metaphor, used not only to establish its features but also the logic of the interfaces. The former drawing oriented CAD software becomes object oriented and focused in the construction of a non-ambiguous model of the designed building. This paper briefly presents the features and resources wanted for an architectural dedicated CAD and the obstacles for its operational utilization.

Keywords: CAD; architectural design; building models.

\section{Introdução}

Os profissionais e empresas envolvidos no projeto de edificações e que vinham utilizando programas CAD orientados ao desenho, estão passando a utilizar CADs específicos, motivados, sobretudo, pela automatização na produção da documentação gráfica do projeto, pela geração automática de dados quantitativos para a elaboração de orçamentos e caderno de encargos, atividades que, quando executadas manualmente, demandam uma quantidade significativa de tempo e extrema atenção (NUNES; CHAPUI; BORGES; REGO).

Programas CAD dedicados ao projeto de arquitetura estão no mercado já há alguns anos, entre eles um desenvolvido por um dos autores deste artigo. ${ }^{1}$ Pela experiência adquirida na concepção e desenvolvimento de programas gráficos, pode-se afirmar que os obstáculos em desenvolver uma ferramenta CAD voltada a uma abordagem integrada do processo de projeto em arquitetura não

\footnotetext{
1 ARCAD 2000 - programa aplicativo para o projeto do edifício, modelagem 2D e 3D integradas, roda associado ao programa AutoCAD 2000 da Autodesk, Inc. Produto operacional de pesquisa desenvolvida no Depto de Arquitetura da Universidade Federal da Paraíba. O programa está disponível para download e experimentação em www.arcad.com.br.
} 
estão na tecnologia disponível em ferramentas de programação e equipamentos, e sim, em uma definição razoável e operacional de quais as atividades de apoio ao projeto de arquitetura, no estabelecimento de padrões e convenções para catalogar partes do edifício, no estabelecimento de padrões para a organização e compartilhamento das informações contidas nos arquivos CAD e nas bases externas de dados, entre outros.

Este artigo pretende levantar, preliminarmente, quais as características e/ou recursos desejáveis em um programa CAD voltado para o projeto de arquitetura e, a partir daí, detectar quais os obstáculos ou impedimentos para a sua implementação operacional. A sua elaboração faz parte da pesquisa de doutorado em Engenharia de Produção que busca mapear as transformações na elaboração e gerenciamento de projetos de edifícios em ambientes informatizados, com ferramentas $\mathrm{CAD}$ e rede de computadores.

\section{A amplitude de utilização no ciclo de projeto}

De uma maneira geral, o que se deseja de uma ferramenta CAD para arquitetura é o apoio informatizado ao ciclo de projeto, abrangendo desde as etapas iniciais de concepção da forma até a etapa final de elaboração da documentação gráfica para a execução.

Mesmo considerando este espectro amplo, estamos excluindo aqui todas as atividades anteriores à tarefa de síntese formal, aquelas atividades que partem de uma mera intenção de edificar e é concluída com o estabelecimento de um programa de arquitetura, onde se determina não só os espaços necessários e suas dimensões, como os critérios de projeto que vão balizar o seu desenvolvimento. As ferramentas CAD dificilmente são utilizadas para este propósito o que justifica esta exclusão. Nesta fase do projeto o que se busca, em grandes linhas, é a verificação da viabilidade econômica do empreendimento e das possibilidades de utilização do lote ou gleba a ser ocupado.

Dentro do intervalo considerado no ciclo de projeto, pode-se ainda separar a etapa inicial de síntese da forma das etapas posteriores de detalhamento e determinação dos materiais, componentes e processos construtivos que vão sendo agregados ao projeto ao longo de seu desenvolvimento. São períodos do ciclo que vão demandar diferentes características da ferramenta CAD utilizada tanto devido às tarefas a serem efetuadas em cada um deles, como devido aos diferentes graus de envolvimento dos membros da equipe de projeto. ${ }^{2}$

A síntese da forma é a atividade onde o arquiteto deve partir de um conjunto de requisitos expostos no programa e do conjunto de expectativas intuídas dos interessados e, propor uma configuração espacial que sintetize estas demandas. É o cerne da atividade profissional do arquiteto e independentemente dos métodos ou técnicas utilizados para a sua execução, é uma atividade onde o conhecimento heurístico é amplamente utilizado. É também predominantemente individual, ainda que o arquiteto possa se valer de consultas a outros arquitetos ou a engenheiros de subsistemas para avaliar e validar as suas propostas ou alternativas de concepção espacial.

As características que se espera de uma ferramenta CAD para esta etapa do projeto são aquelas que facilitam a criação, visualização e manipulação dos componentes físicos tridimensionais que conformam os espaços projetados. O projeto da interface homem-máquina é fundamental para o estabelecimento de um mundo de projeto

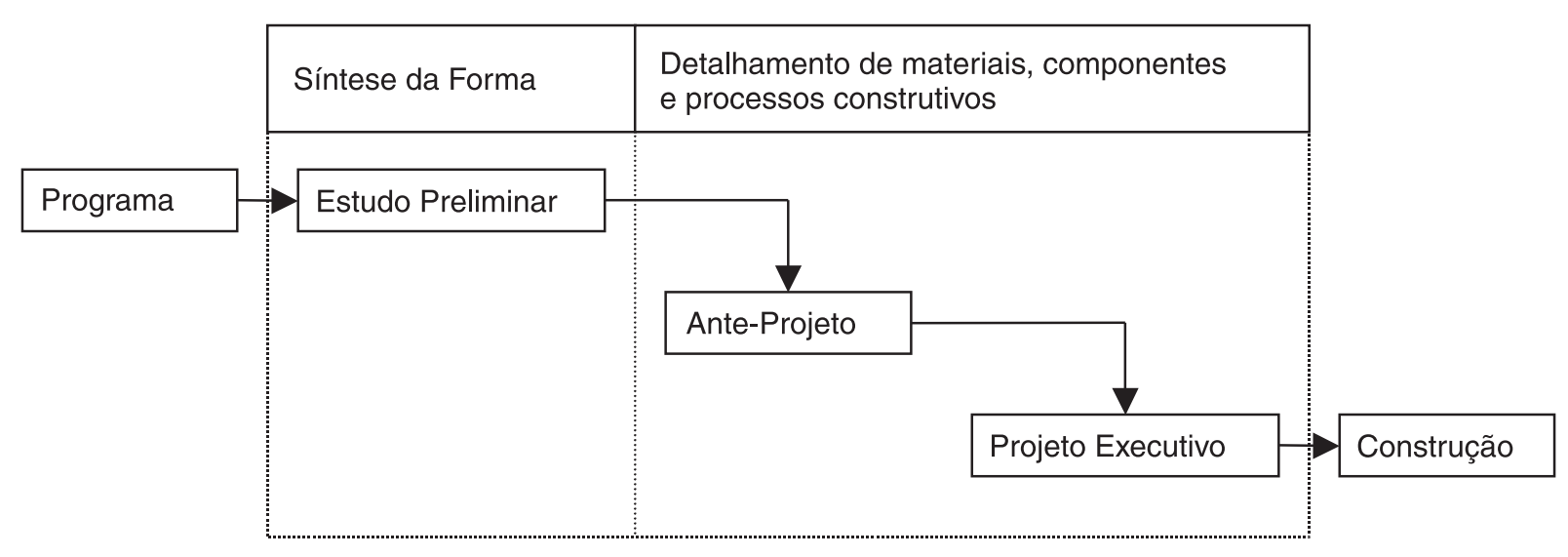

Figura 1 - A identificação das etapas onde as ferramentas CAD têm funções diferenciadas, no ciclo de projeto

\footnotetext{
2 Uma das características notáveis na utilização de ferramentas CAD é a redução do número de etapas necessárias à elaboração de um projeto.
} 
virtual, intuitivo e veloz o suficiente para apoiar a modelagem e a avaliação de configurações espaciais criadas pelos arquitetos. ${ }^{3}$

As etapas seguintes consistem basicamente em agregar, à configuração espacial arquitetônica de partida, uma enorme massa de informações que vão resultar, ao final do ciclo, na especificação de um modelo digital do edifício com os dados e as informações necessárias, suficientes e não-ambíguas para a sua construção.

Nestas etapas, as ferramentas CAD vão apoiar o desenvolvimento do projeto de duas formas: a) facilitando a incorporação de novas informações geométricas, semânticas e numéricas ao modelo, assegurando a sua consistência interna e o relacionamento com as outras informações, e b) permitindo o compartilhamento dos arquivos contendo o modelo do edifício entre os diferentes membros da equipe de projeto. São funções que dizem respeito basicamente ao gerenciamento das informações de projeto e são dependentes da estrutura organizacional com que se está trabalhando.

\section{As características gerais}

São apresentadas, a seguir, algumas das características gerais desejáveis de uma ferramenta $\mathrm{CAD}$ para o projeto e a representação do edifício. Algumas delas já estão presentes na grande maioria das ferramentas CAD profissionais como, por exemplo, a modelagem e a visualização tridimensional de sólidos e superfícies, e a geração automática - em vários graus de acabamento e detalhes - dos desenhos 2D que fazem parte da documentação gráfica do projeto.

Mesmo assim, destacamos que uma ferramenta CAD voltada para uma abordagem integrada ao projeto de arquitetura, deve apresentar todo o conjunto articulado de características que são:

\subsection{Concepção espacial através de modelagem 3D orientada ao objeto}

Esta é uma característica importante para a primeira etapa do projeto de arquitetura, a da determinação da síntese da forma. Uma boa parte dos arquitetos que se formaram e desenvolveram as suas atividades antes da existência de computadores argumenta que as ferramentas CAD não são as mais adequadas para esta tarefa, preferindo a utilização de desenhos elaborados manualmente. ${ }^{4}$

A dificuldade aqui é a passagem de um mundo de projeto $^{5}$ onde a ferramenta auxiliar de registro e de diálogo interativo com o objeto deixa de utilizar linhas e entidades gráficas bidimensionais para a manipulação direta de formas tridimensionais. Mudam não só os componentes da linguagem e a sua sintaxe, como os dispositivos físicos que transmitem as idéias para o suporte de registro - do lápis e papel para o mouse e o monitor de vídeo -, o que demanda dos arquitetos o aprendizado desta nova linguagem e de um novo gestual para o diálogo homem - ferramenta CAD. Esta linguagem e os dispositivos físicos devem permitir com presteza a descrição de formas arquitetônicas ou componentes construtivos da edificação para a sua representação através de modelos 3D.

As vantagens de utilizar modelos tridimensionais na concepção de projetos de arquitetura são evidentes, a começar pela possibilidade de visualizar interativamente um modelo do edifício de uma maneira mais próxima como será visto por seus futuros usuários. Além de seu caráter unívoco, outras vantagens significativas decorrentes da utilização da tecnologia de modelagem 3D são a independência relativa entre o modelo e as formas de apresentação de sua documentação gráfica, e as facilidades na quantificação e na simulação do comportamento da edificação ou de seus componentes.

\subsection{Do geral para o particular, numa abordagem incremental}

Com raras exceções, é este movimento que caracteriza o desenvolvimento de um projeto: de forma geral da edificação ao detalhamento para a produção; do relevante ao preciso.

A ferramenta CAD deve oferecer uma interface e um método de agregação de dados e informações gráficas ao modelo do edifício que permita, a partir de decisões gerais sobre a forma e o posicionamento dos componentes da edificação, prosseguir detalhando-os até que estejam claramente caracterizados para a construção.

\footnotetext{
3 A falta de uma interface intuitiva e veloz (de resposta rápida) tem sido uma das deficiências apontadas por um bom número de arquitetos no uso de ferramentas CAD nas fases iniciais do projeto.

4 Não é nosso propósito polemizar neste debate, mas é fácil verificar um "verdadeiro fetiche" em relação ao desenho manual por parte dos arquitetos. De um instrumento dialógico para o desenvolvimento da síntese espacial (REGO), o desenho passa a ser um fim em si mesmo e os arquitetos passam a ser reconhecidos como profissionais que produzem belos desenhos, e não como profissionais que elaboram bons projetos.

5 Mundos de projeto ou ambientes de concepção (design worlds) são ambientes de trabalho que dispõem de símbolos gráficos que podem ser manipulados de acordo a certas regras gramaticais. O processo de projetos seria visto como computações em mundos de projeto com o objetivo de satisfazer predicados de forma e função estabelecidos em uma linguagem crítica (MITCHELL).
} 
O modelo vai sofrendo acréscimos, complementações, revisões e supressões de dados e informações à medida que decisões compartilhadas com outros autores vão sendo tomadas.

A necessidade de informar detalhes desnecessários de componentes nas etapas iniciais do projeto pode desviar o arquiteto de sua linha de raciocínio de concepção espacial do conjunto. Um bom exemplo é o de modelagem de esquadrias. Nas fases iniciais do projeto, um arquiteto, ao posicionar uma porta de acesso a um cômodo, está apenas preocupado em racionalizar os fluxos de circulação. Se a interface para a modelagem de uma porta, além das dimensões do vão e do sentido de abertura das folhas, pede a determinação da cor, dos materiais e dos acabamentos das folhas e aros, do tipo de dobradiça, da especificação da maçaneta, do código de identificação e do material dos aros, certamente a sua determinação vai levar mais tempo. É claro que estas informações vão ser necessárias ao final do projeto, mas a sua escolha pode ser feita mais adequadamente em uma etapa posterior, onde o posicionamento e as dimensões da porta já estejam definitivamente estabelecidos, e até mesmo por outro profissional da equipe.

A implantação desta característica em uma ferramenta CAD vai implicar em um projeto de interface sensível ao contexto, onde as informações são solicitadas à medida que o modelo vai se detalhando. A estrutura de armazenamento dos dados deve ser flexível de forma não só a facilitar o acréscimo paulatino destas informações com rebatimento na representação gráfica do componente quando necessário, como também para alertar ao usuário se faltam elementos de caracterização do modelo ou de um componente.

\subsection{Automatização da produção de desenhos 2D}

Isto significa a elaboração automática de desenhos tais como plantas baixas, cortes e elevações, e toda e qualquer projeção bidimensional a partir do modelo tridimensional contido no arquivo CAD.

Construído um modelo tridimensional do edifício, basta indicar a posição e o sentido das vistas - geralmente ortogonais - para que a ferramenta CAD construa desenhos bidimensionais representando a projeção indicada. A atualização destes desenhos pode também ser automática e à medida que modificações são efetuadas no modelo tridimensional. A questão a superar aqui diz respeito à automatização do desenho da chamada "anotação", ou seja, textos explicativos, símbolos, cotas e hachuras necessárias à compreensão dos desenhos.

Se o desenho das projeções dos componentes modelados tridimensionalmente - os sólidos e as superfícies não apresenta dificuldades, uma boa parte da anotação ainda tem que ser acrescentada manualmente pelo usuário. Anotação é o nome dado a toda informação agregada ao conjunto de entidades gráficas do projeto tais como textos explicativos, cotas e o preenchimento de áreas com padrões de hachuras. Os obstáculos para a automatização do desenho das anotações, pelo menos uma boa parte delas, estão: a) na obsolescência da norma brasileira para o desenho de arquitetura - NB-49 de 1994 - anterior ao surgimento e à disseminação de ferramentas CAD, e b) a necessidade de adesão dos profissionais e empresas do setor de AEC aos padrões estabelecidos nas normas. ${ }^{6}$

Nas representações de projeto elaboradas manualmente, o desenho da anotação sempre foi uma das tarefas mais demoradas e tediosas, não raramente executada por "especialistas" em grandes projetos para assegurar a consistência e aumentar a produtividade. Nestas circunstâncias, a tendência era também reduzir ao mínimo necessário a anotação desenhada, transferindo estas informações para tabelas e textos em outros documentos.

As possibilidades da automatização do desenho da anotação em sistemas CAD dedicados vêm inverter este processo. Se o desenho da anotação não é mais uma tarefa separada a ser realizada pelo operador, já que ela pode ser automaticamente desenhada no momento em que um componente da edificação é definido, a sua utilização pode e deve ser ampliada no sentido de agregar mais informações aos desenhos que formam a representação gráfica do projeto. O posicionamento da anotação no próprio desenho e não em documento de texto ou uma tabela à parte já é uma providência que aumenta consideravelmente a consistência e clareza da documentação do projeto, mas para que as ferramentas CAD possam automatizar verdadeiramente o desenho destes componentes do desenho, é necessário que a anotação seja, o tanto quanto possível, uma anotação dita "acoplada" (CORDEIRO, 1996). Este termo denomina aquele tipo de anotação que faz parte da representação do componente ou parte da edificação tanto como as entidades gráficas - linhas, arcos - que o representam, tais como os símbolos de identificação de esquadrias, a numeração dos degraus de uma escada, o sentido da

\footnotetext{
6 Além da obsolescência da norma verifica-se o seu descumprimento geral por parte dos arquitetos. Esta não adesão à norma não se deve ao fato de estar desatualizada, mas pelo equívoco de uma boa parte dos arquitetos em buscar uma aparência expressiva, singular e pessoal em desenhos que deveriam, antes de tudo, ser claros, precisos e padronizados. A relação forma/função é que tem que ser criativa e não a sua representação.
} 


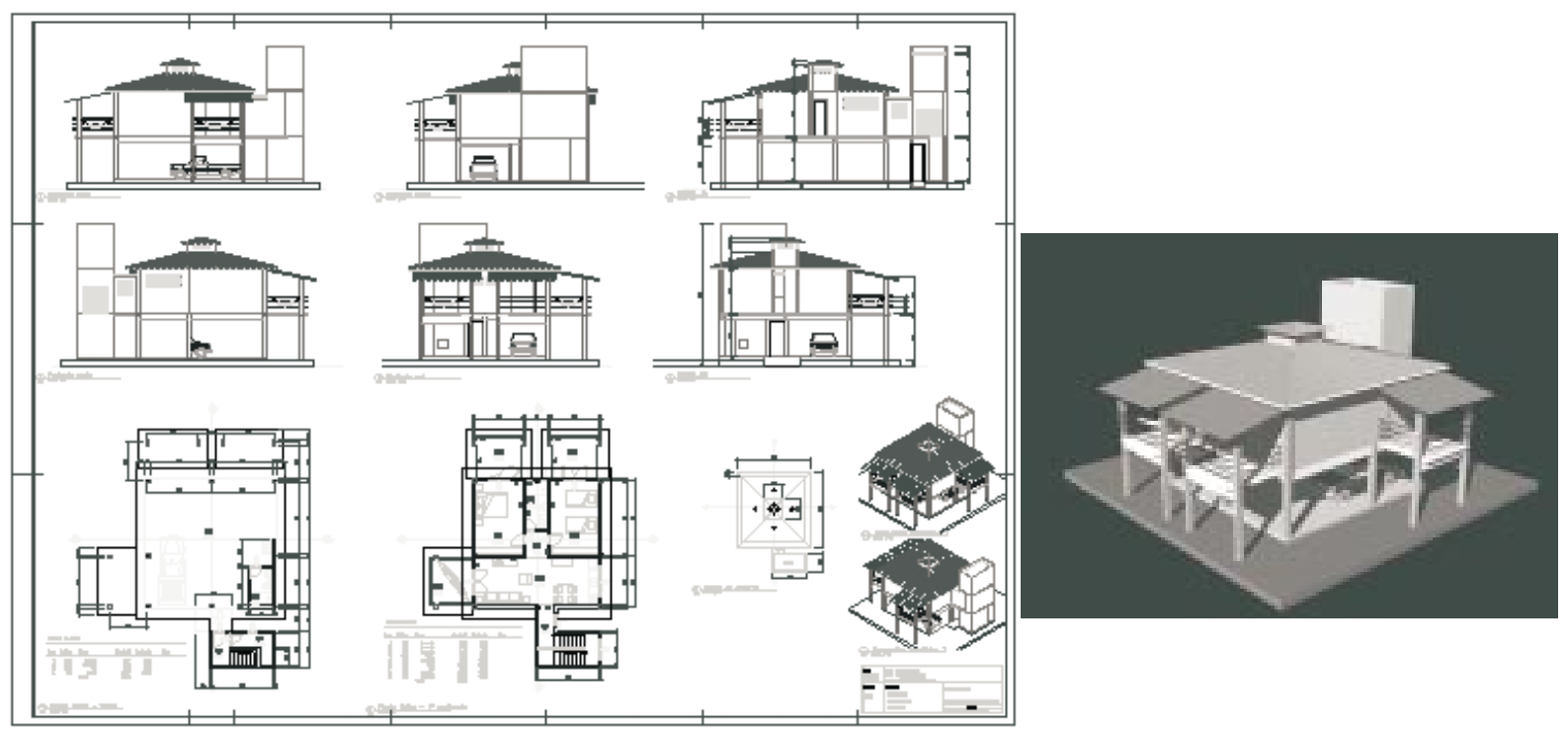

Figura 2 - A elaboração dos desenhos 2D como instâncias de visualização do modelo 3D. A partir do posicionamento do ponto de vista e do tipo de projeção - cilíndrica ou cônica - para o modelo 3D à direita foram automaticamente gerados todos os desenhos que estão na prancha à esquerda. Parte de anotação foi acrescentada manualmente.

declividade de rampas e telhados e o padrão de hachura para indicar o material utilizado. Este é o tipo de anotação que normalmente é definido em norma e a tendência passa a ser de incrementar o número de anotação acoplada de forma a que estas informações adicionais aumentem o entendimento das representações e a consistência das informações do projeto.

\subsection{Extração automática de dados do modelo}

Esta característica se faz presente através dos recursos da ferramenta CAD para a geração automática de quantitativos totais ou parciais de materiais, componentes, equipamentos, áreas e volumes de construção. A utilização de modelos tridimensionais do edifício facilita a implementação destes recursos de forma mais precisa, além de permitir a atualização automática dos quantitativos toda vez que o modelo for modificado.

A quantificação automática e imediata do modelo do edifício ou de seus componentes é de utilidade tanto na etapa inicial do projeto, a de concepção da síntese da forma, como nas etapas posteriores de detalhamento. Nos momentos iniciais do projeto, estas ferramentas de quantificação permitem comparar diferentes configurações espaciais ou verificar se uma configuração espacial específica está de acordo com as áreas e custos previstos inicialmente no programa de necessidades. Nas fases subseqüentes, estes quantitativos podem e devem ser mais detalhados e específicos, permitindo um controle permanente e em tempo real sobre os aspectos quantitativos do projeto.
Mais do que as vantagens de ganhos em produtividade e qualidade do projeto que estes recursos possibilitam, está o enorme alívio de não ser mais necessário quantificar, manualmente, uma tarefa repetitiva, aborrecida e sujeita a erros.

Existem dois grandes obstáculos para uma implementação funcional e confiável para esta característica que são: a) como vão ser classificados os componentes extraídos do modelo, e b) qual o formato de exportação dos dados extraídos de forma a que possam ser impressos e/ ou serem utilizados como dados de entrada para outros programas como, por exemplo, o aplicativo que prepara o orçamento. O fator agravante é que estes são obstáculos que devem ser superados simultaneamente, dada a interdependência que deve existir entre as duas soluções.

Os sistemas de classificação para partes e/ou componentes de uma edificação proporcionam uma categorização detalhada das informações da construção de acordo com critérios específicos. Por exemplo, eles podem categorizar tipos de edificações de acordo com o seu propósito principal - fábricas, hospitais, rodovias, etc.), tipos de espaços de acordo com o seu uso espaços de escritórios, espaços de dormir, espaços de trabalho - ou tipos de elementos físicos do edifício de acordo com a sua forma ou função - paredes, pisos, elementos da instalação elétrica.

Estas categorizações permitem a montagem de tabelas de classificação que listam o código, nome e a descrição de cada item. Sistemas de classificação padronizados podem oferecer um mecanismo de estruturar a informação do projeto - contida em documentos, bases de dados ou modelos - de uma forma consistente ao longo da indústria da construção civil. 


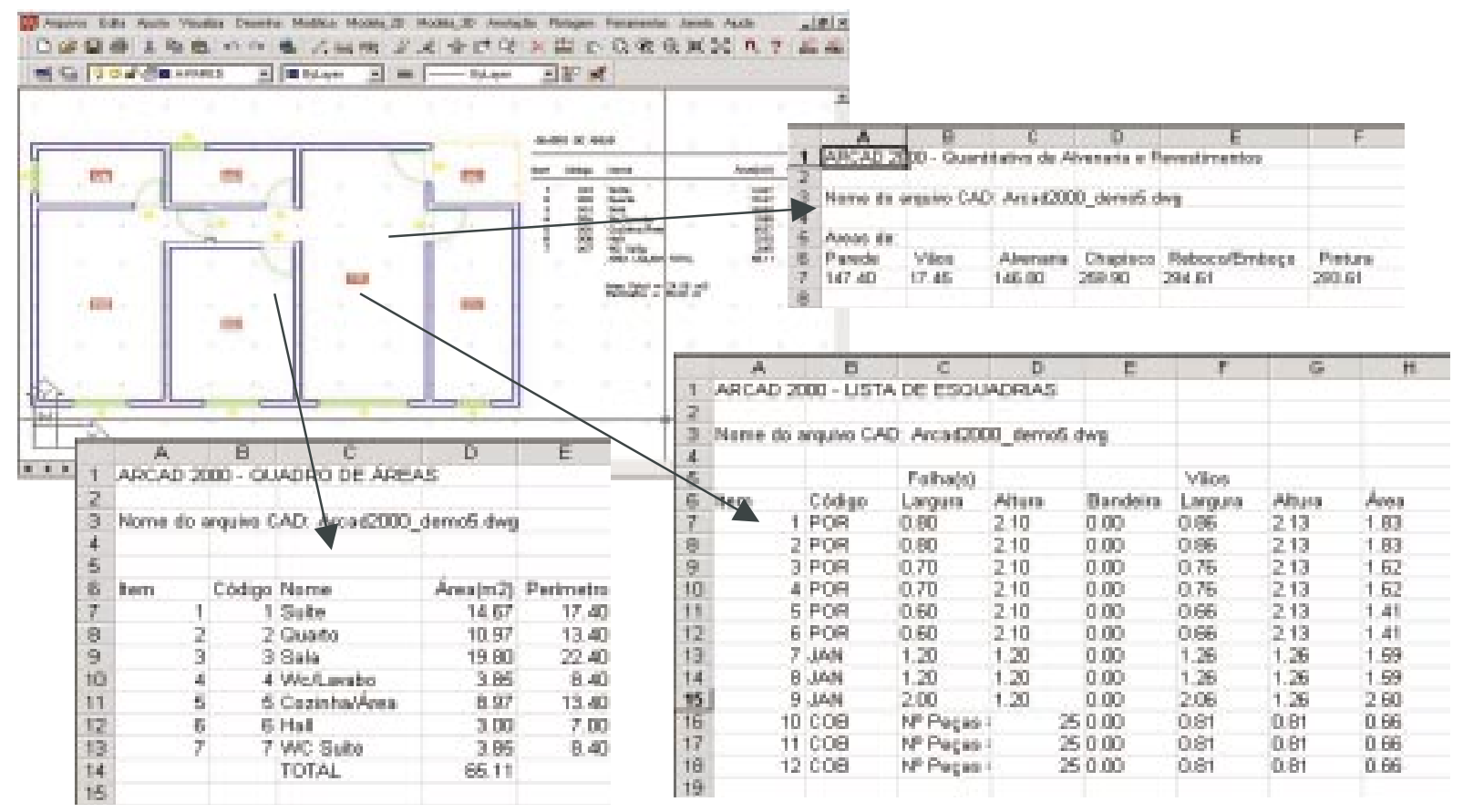

Figura 3 - A extração automática de dados do projeto. No exemplo, a ferramenta CAD "varre" o desenho 2D da planta baixa, e exporta os dados de forma a serem utilizados por planilhas eletrônicas.

O estabelecimento de sistemas de classificação de edificações é um tema que vem sendo intensamente debatido em todo o mundo, sendo objeto de padrões nacionais, de padrões para grupos específicos de usuários ou setores industriais, e de uma proposta de norma internacional. Sistemas de classificação da edificação e seus componentes têm uma enorme importância no desenvolvimento de CAD dedicados ao projeto de arquitetura não só pelas possibilidades de extrair quantitativos e lista de materiais, mas na organização e codificação da base de dados dos componentes do modelo informatizado, nas facilidades de compartilhamento de informações e, até mesmo, na concepção da interface homem-máquina.

Dada a dificuldade de estabelecer um sistema único de classificação como padrão internacional, o esforço mais recente, proposto como relatório técnico pela ISO - International Standartization Organization - apresenta um sistema de classificação orientado a objetos, ou seja, semanticamente orientado de forma a que possa ser articulado com os diferentes sistemas de classificação e codificação já utilizados em vários países. ${ }^{7}$

No Brasil, uma das iniciativas mais consistentes neste propósito vem sendo desenvolvida através do Projeto
CDCON - Desenvolvimento de Terminologia e Codificação de Materiais e Serviços para Construção - que tem como objetivo "obter um consenso em torno de uma sistemática padronizada para terminologia e uma norma de conteúdo para a codificação da construção" e que se constitua em um projeto de Norma Brasileira. Este projeto tem a participação de várias universidades, da Associação Nacional dos Comerciantes de Material de Construção e é apoiado por entidades governamentais financiadoras de pesquisa (CNPq e Finep). Seus propósitos, realizações e cronograma de pesquisa estão disponíveis em página própria na internet e que pode ser acessado em http://www.cdcon.ufjf.br/projeto/apresentacao.php.

Além da adoção de um sistema de classificação por toda a indústria de Arquitetura, Engenharia e Construção AEC -, um outro obstáculo a ser superado quanto à quantificação de materiais, componentes e tarefas na construção provém dos procedimentos estabelecidos para as quantificações, baseados em processos manuais de levantamento e com aproximações desnecessárias frente à precisão e automatismo dos cálculos informatizados. O procedimento para descontar os vãos de esquadrias no cálculo dos revestimentos de alvenarias é um bom exemplo. Os vãos não são integralmente subtraídos das áreas de revestimentos para "compensar" o trabalho extra

7 ISO/DIS 12006-2: Building Construction. Organization of Information about construction works - Part 2: Framework of classification of information

ISO/DPAS 12006-3: Building Construction. Organization of Information about construction works - Part 3: Framework for object-oriented information exchange. 
para o acabamento das arestas criadas com a abertura da esquadria, os denominados "capiaços".

\subsection{Controle e gerenciamento do tempo de produção e dos arquivos do modelo}

Esta característica abrange o conjunto de recursos para a criação, armazenamento e recuperação de todos os arquivos e documentos digitais do projeto, considerando suas diferentes fases de desenvolvimento, e para as diferentes disciplinas envolvidas no processo e de acordo com um padrão de nomenclatura. Estes recursos devem também medir o tempo de trabalho dedicado ao projeto, discriminado por arquivo, de forma a facilitar o gerenciamento do tempo dedicado a cada trabalho ou tarefa, e para o cálculo do custo do projeto. Uma implementação operacional destas características está em um programa aplicativo para o gerenciamento de projetos de edifício - o Ariadne - disponível na internet para descarga e instalação em www.arcad.com.br e desenvolvido por um dos autores deste artigo.

A utilização de recursos informatizados para estas tarefas traz como benefício imediato a padronização no nome dos arquivos e pastas armazenados digitalmente, com a conseqüente facilidade em encontrá-los e recuperá-los, além da impossibilidade de sobrescrever arquivos distintos e com o mesmo nome. Estes acidentes acontecem com uma certa freqüência até mesmo em situações em que apenas um computador é utilizado na elaboração do projeto. Em ambientes dotados de rede de computadores, o gerenciamento da nomenclatura e integridade dos arquivos $\mathrm{CAD}$, mesmo com normas escritas e detalhadas como se deve proceder, só é confiável quando controlado por programas aplicativos que tomam para si as tarefas de nomear e gravar os arquivos no local adequado.

O gerenciamento inadequado de arquivos digitais tem sido um problema que acompanha a informatização em várias áreas de atividade. Na prática atual, o gerenciamento geral da documentação tem sido freqüentemente tomado como um item de responsabilidade e solução pessoal, na melhor das hipóteses manuseado dentro de um escritório, mas raramente ao nível de projeto. $\mathrm{O}$ estado de arte da pesquisa nesta área pode ser grosseiramente dividido nas duas abordagens:

a) A abordagem do gerenciamento integrado de documentos. Os documentos são tratados como caixas-pretas e o alvo do suporte por computador é habilitar a fácil recuperação usando informações de referência. Esta abordagem está começando a tornar-se prática tendo em vista a proliferação dos sistemas chamados de EDM - Eletronic Document Management. b) A abordagem baseada em modelos. Nesta abordagem, toda informação, que tradicionalmente era contida nos desenhos e documentos de texto, é armazenada em uma única base de dados integrada onde a informação pode ser recuperada usando perguntas, e os documentos escritos podem ser produzidos quase sempre automaticamente. Em ambos os casos, o aplicativo percorre a base de dados do modelo e recupera as informações pertinentes à resposta, relatório ou ao documento escrito que se deseja.

As desvantagens encontradas na primeira solução dizem respeito: a) à necessidade de estabelecer manualmente o relacionamento semântico que os arquivos devem ter entre si, e b) à dificuldade de atualização automática de documentos e relatórios quando o modelo é atualizado.

Já a abordagem baseada em modelos tem como a maior desvantagem o grande tamanho do arquivo digital contendo não só as informações e dados relativos à posição e à forma geométrica do modelo tridimensional, como as informações semânticas e de propriedades associadas a suas partes e componentes.

Seja qual for a abordagem adotada, o gerenciamento dos arquivos digitais do projeto é uma tarefa importante e fundamental para a fluidez do fluxo de trabalho em ambientes informatizados de projeto. Proporcionar recursos que ajudem a levá-la adiante é uma das características desejáveis na concepção de ferramentas CAD. Dado o sistema de atribuição da responsabilidade técnica de profissionais engajados na elaboração de projetos de edificações, este gerenciamento tem que possibilitar, também, o registro e a identificação da contribuição individual de cada profissional.

\subsection{Gerenciamento e produção automatizada dos arquivos a serem compartilhados}

Esta característica tem como objetivo principal apoiar o compartilhamento de arquivos CAD contendo o modelo do edifício entre os diferentes profissionais e interessados envolvidos no projeto e em suas diversas etapas. O gerenciamento abrange o registro da informação de quais os arquivos compartilhados, como a informação é acrescentada a estes arquivos, como identificar os conflitos de projeto entre os diferentes subsistemas e qual a solução acertada.

Os problemas de implementação quanto a este item são as diferentes necessidades entre os participantes do processo de projeto quanto às características do modelo e/ ou suas representações. De uma forma geral, parece ser de difícil concretização a produção de um único modelo para apoiar todos os participantes do processo de projeto. 
As conclusões das investigações mais recentes sobre este assunto apontam para a necessidade de um conjunto de modelos ou de representações singulares às disciplinas específicas e articulados entre si.

Um exemplo significativo pode ser a inutilidade ou a dificuldade de utilizar um modelo tridimensional para o projeto de instalações elétricas. As vantagens do modelo $3 \mathrm{D}$, tão evidentes para o arquiteto ou para o engenheiro de estruturas, não o são para o engenheiro eletricista que utiliza, para a representação de seu subsistema, um conjunto de símbolos gráficos sem nenhuma semelhança morfológica com os componentes reais do sistema de instalações elétricas.

A complexidade advinda desta necessidade em utilizar múltiplos modelos e formas de representação articulados e compatíveis entre si vai se refletir em dificuldades no gerenciamento do processo de projeto. Alguns autores sugerem que os modelos podem ser mais facilmente articulados e compreendidos se informações semânticas contendo o propósito ou a intenção daquele componente ou parte são associadas às entidades gráficas (ROSEN-MAM, 1999). De qualquer forma, as ferramentas CAD devem estar preparadas para receber, catalogar e apresentar esta informação quando for necessário.

\subsection{Simulações funcionais de desempenho do modelo}

A utilização de modelos tridimensionais do edifício em arquivos $\mathrm{CAD}$ possibilita, de imediato, simulações de desempenho formal, uma valiosa ferramenta para a concepção do projeto e para aprovação por parte dos envolvidos nos processos de decisão, leigos ou não. Simula- ções de eficiência energética e de estabilidade estrutural estão também entre aquelas mais facilmente realizadas a partir de modelos tridimensionais informatizados. A validade desta e de outras simulações possíveis com modelos 3D vão estar diretamente ligadas à semelhança morfológica e semântica entre o modelo e o edifício real, ou seja, na capacidade da ferramenta CAD em promover estas semelhanças.

A simulação de desempenho, com o auxílio de ferramentas informatizadas, tem uma maior importância do setor de AEC pela impossibilidade, na maioria das situações, de se utilizar protótipos funcionais como é comum em outros ramos industriais produtores de artefatos.

Por outro lado, dada a ambigüidade inerente aos requisitos de programa para o projeto arquitetônico, as simulações adquirem um papel fundamental dentro dos ciclos análise-síntese-avaliação na concepção do edifício, principalmente na fase inicial do projeto. É durante esta etapa que as decisões mais importantes e estratégicas são tomadas quanto à implantação no espaço urbano, quanto à disposição dos espaços edificados e quanto à forma final da edificação. Ferramentas CAD que facilitem o entendimento dos diversos interessados no projeto incorporador, usuários, engenheiros de projetos complementares e outros - acerca da proposta físico-espacial quanto a sua aparência e seu desempenho, vão contribuir efetivamente para uma melhoria deste processo decisório.

\subsection{Acesso à base de dados externos}

A elaboração de projetos de edificações demanda o acesso a um grande volume de dados e informações. Nas etapas iniciais do projeto a busca é geralmente por soluções dadas por outros arquitetos a problemas seme-

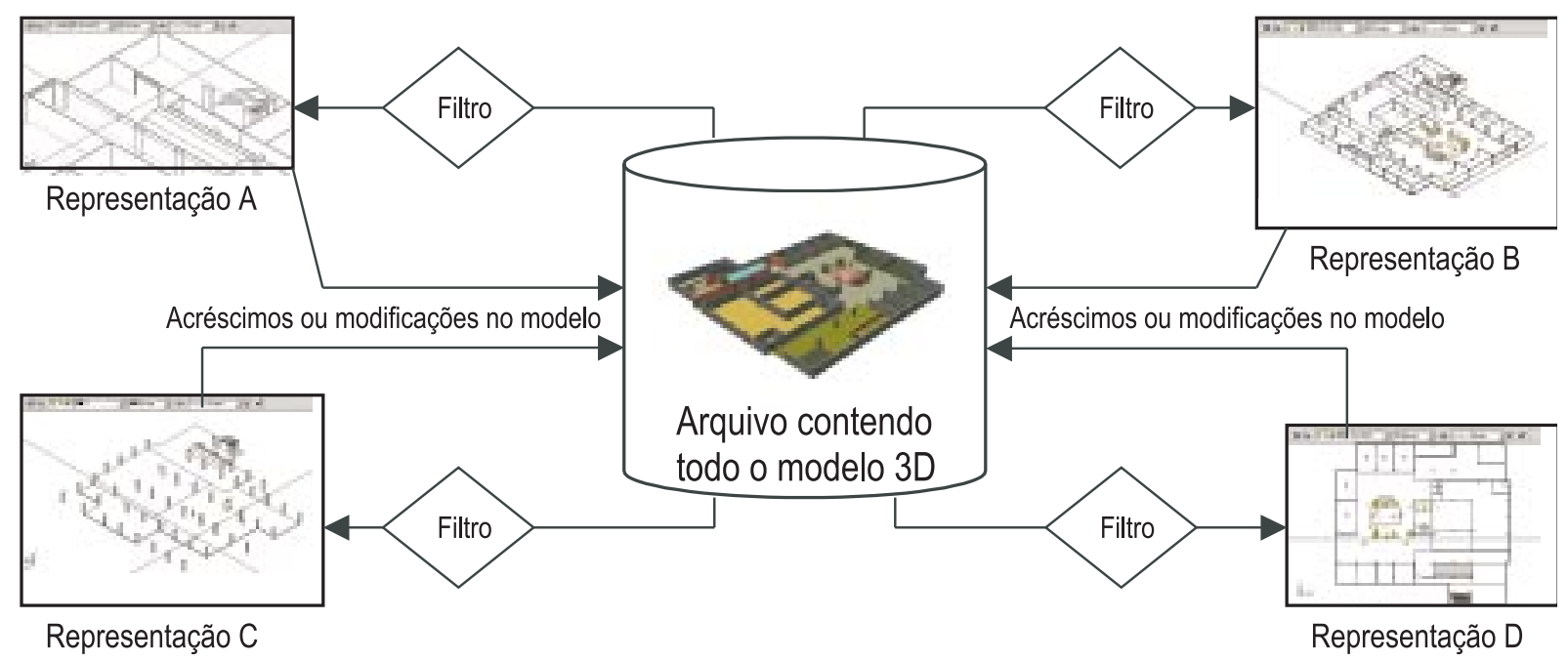

Figura 4 - O compartilhamento do modelo do edifício entre os diferentes projetistas. Para cada projetista um tipo especial de representação é oferecido "filtrando-se" do modelo completo os dados, partes e informações desnecessárias à concepção a ser realizada. A contribuição de cada projetista é incorporada ao modelo completo do edifício que por sua vez volta a compartilhar estas informações entre os outros projetistas. 
lhantes ou similares. É o que se chama no jargão profissional de adquirir ou incrementar um "repertório arquitetônico". Ainda nestas etapas é fundamental o acesso não só à legislação urbana que determina o uso e a ocupação possível do lote disponível, como todas as normas que influenciam - e às vezes determinam - a forma construída, tais como regulamentos de proteção contra incêndio, normas de acesso a deficientes e as exigências das empresas concessionárias de infra-estrutura de água, esgotos, energia elétrica. Já durante as fases subsequientes, a busca é por informações que permitam o detalhamento do projeto quanto às especificações dos materiais, dos componentes $\mathrm{e}$ equipamentos, dos processos construtivos e/ou montagem, assim como padrões de desempenho e exigências de manutenção.

Tal volume de informações diferenciadas não cabe internamente em uma ferramenta $\mathrm{CAD}$, mesmo porque uma boa parte delas muda constantemente, seja o aperfeiçoamento e o lançamento de uma nova versão de uma norma, o lançamento de novos produtos ou processos, ou a mudança das especificações de um componente. Além do mais, este conjunto de informações é gerado por diversas entidades, instituições e empresas de forma que eles não se encontram em uma única base de dados.

Nestas condições, a solução viável é dotar a ferramenta $\mathrm{CAD}$ de recursos para o acesso a diversas bases externas de dados, onde estas informações podem ser recuperadas e transferidas para o ambiente de projeto. Nunca é demais ressaltar aqui a importância de taxonomias ou sistemas de classificação que permitam dar um sentido semântico único ou pelo menos articulado entre os dados destas diversas fontes de informação.

A rede mundial de computadores conectados através da internet tem sido majoritariamente a solução tecnológica utilizada como suporte para a manutenção e o acesso a estas bases de dados. O problema aqui não é a disponibilidade da informação em si, mas o de "filtrar" a informação desejada dentro do enorme volume de informações disponível na internet.

Neste sentido, o esforço mais recente é a utilização da linguagem de programação XML que possibilita a inclusão de definições semânticas em arquivos disponíveis pela internet. O desenvolvimento de uma linguagem específica - aecXML - baseada na linguagem XML com o propósito de ser utilizada para representar a informação do setor de Arquitetura, Engenharia e Construção é a missão a que se propõe a IAI - International Alliance for Interoperability, seja esta informação composta de recursos tais como projetos, documentos, materiais, partes, organizações profissionais, como de atividades tais como a elaboração de propostas, apresentação de concepções, cronogramas e a construção. ${ }^{8}$

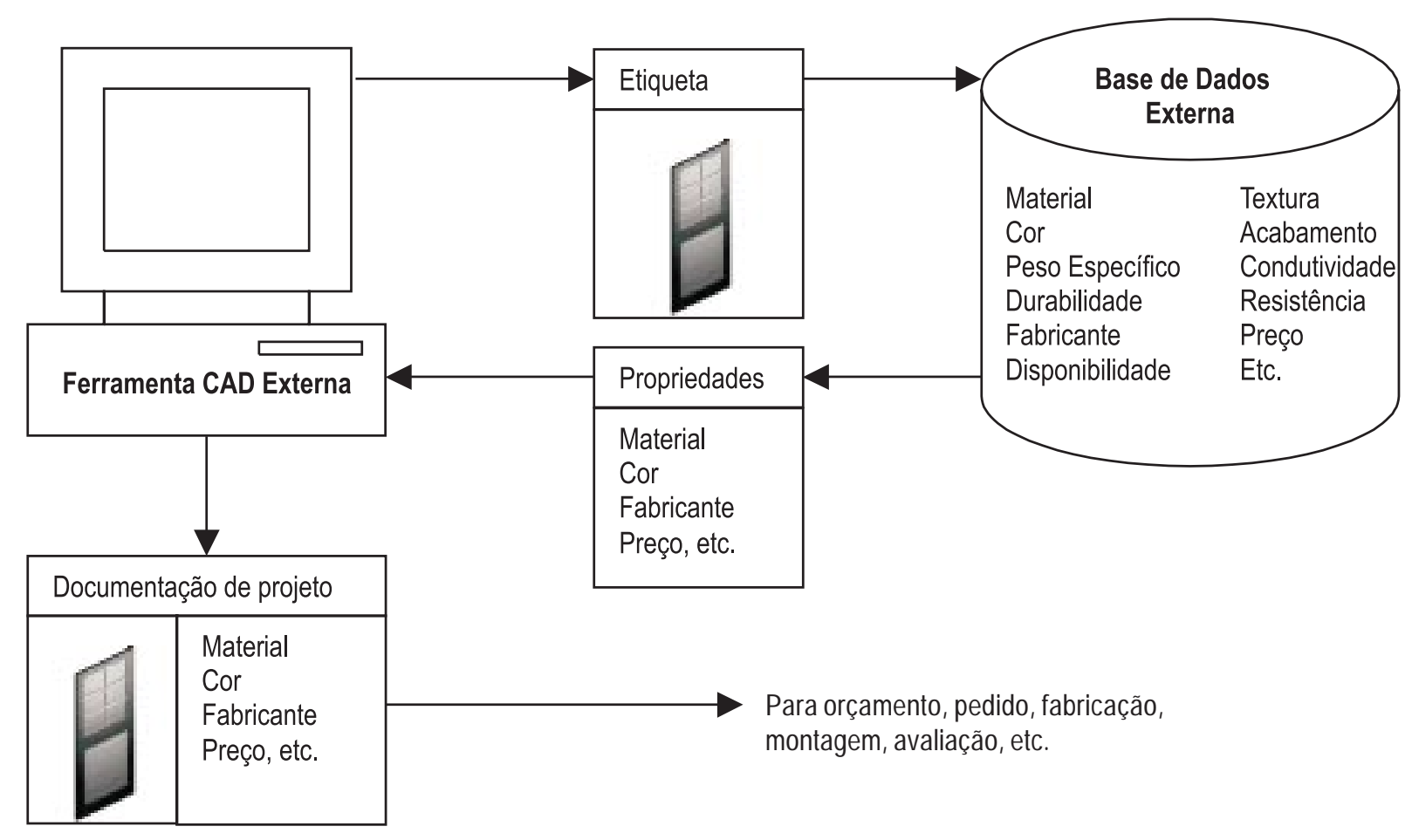

Figura 5 - O acesso a base de dados externas via internet e de forma automática - como são, por exemplo, as atualizações de programas antivírus - permitem estender a vinculação entre os aspectos geométricos do componente construído em uma ferramenta CAD com as suas características e propriedades, em tempo real. 


\section{Conclusões}

A intenção deste artigo foi a de mostrar, em grandes linhas, as características desejáveis para uma ferramenta CAD para o projeto de arquitetura. Independentemente da aceitação destas características ou da omissão de outras, a tese central aqui defendida é que os obstáculos à implementação de ferramentas CAD com estes recursos estão muito mais ligados às deficiências gerenciais e de padronização de produtos e processos da indústria de AEC do que às tecnologias disponíveis em equipamentos e no desenvolvimento dos algoritmos e códigos dos programas. A necessidade de uma reorganização produtiva nas organizações deste setor parece ser o passo necessário ao estabelecimento de ambientes de projeto informatizados e mais produtivos.

Parece ser oportuna a tarefa de investigar mais a fundo estas características, buscar delimitá-las mais apropriadamente e trazer à tona os obstáculos em termos organizacionais e de demandas de padronização para a concepção de ferramentas CAD dedicadas e para uma melhor integração em ambientes informatizados de projeto.

\section{Referências}

AMORIM, S. R. L. et al. Specification Standards for the new Management settings of Construction. In: Proceedings IGLC-10, Gramado, Brasil, 2002.

BORGES, M. M. A projetação e as formas de representação do projeto. Dissertação de Mestrado, COPPE/ UFRJ, Rio de Janeiro, 1998. 130p.

CHAPUIS, F. A difusão de Sistemas CAD em escritórios de arquitetura. Dissertação de Mestrado, Faculdade de Arquitetura e Urbanismo, Universidade Federal do Rio de Janeiro, Rio de Janeiro, 1995. 165p.

CORDEIRO, A. L. de M. O uso de sistemas CAD como instrumento de integração na produção de edifícios.
João Pessoa, 1996. Dissertação de Mestrado, Centro de Tecnologia da Universidade Federal da Paraíba. 165p.

LAWSON, B. How designers think. 2. ed. London: Butterworth Architecture Ed, 1990. 243p.

MITCHELL, W. J. The logic of architecture: design, computation and cognition. 4. ed. Massachusetts, EUA: The MIT Press, 1994. 192p.

NOACK, R. Converting CAD Drawings to Product Models. Licentiate Thesis, Division of Construction Management and Economics, Department of Real Estate and Construction Management, Royal Institute of Technology, Stockholm, Sweden, 2001, 71p.

NUNES, R. C. P. Implementação e padronização de sistemas CAD: uma análise dos escritórios de projeto no Rio de Janeiro. Niterói, 1997. Dissertação (Mestrado). Escola de Engenharia Civil da Universidade Federal Fluminense. 149p.

REGO, R. de M. Arquitetura e tecnologias Computacionais: novos instrumentos mediadores e as possibilidades de mudança no processo projetual. Salvador, 2000. Dissertação de mestrado, Faculdade de Arquitetura da Universidade Federal da Bahia. 173p il.

REZGUI, Y.; DEBRAS, P. An Integrated Approach for a Model Based Document Production and Management. Information Technology Institute, Computer Integrated Construction Division, University of Salford, 1995, UK.

ROSENMAM, M. A.; GERO, J. S. Purpose and function in a collaborative CAD environment. Sydney, 1999. In: Reability Engineering and System Safety, 64:167-169

WOESTENENK, K. The Lexi-Con: a new tool for reengineering the construction design/supply chain. In: International Conference on Construction Information Technology, INCITE 2000, Hong Kong, 17-18 January, 2000.

\footnotetext{
8 A missão, atividades e propostas da IAI podem ser encontradas em http://www.iai-na.org/aecxml/mission.php
} 


\section{Produto \& Produção}

\section{Política editorial e normas para publica- ção de artigos}

Publicação quadrimestral (tiragem em fevereiro, junho, outubro) do Programa de Pós Graduação em Engenharia de Produção da Escola de Engenharia da Universidade Federal do Rio Grande do Sul.

\section{Política Editorial}

São aceitos artigos de interesse da Engenharia de Producão, nas áreas de Gerência de Produção, Qualidade, Gestão Econômica, Ergonomia e Segurança do Trabalho, Engenharia do Produto, Pesquisa Operacional, Estratégia e Organizações, Gestão da Tecnologia, Sistemas de Informação e Conhecimento, Gestão Ambiental e Ensino de EP. Os trabalhos devem ser originais ou divulgados previamente de forma restrita, contendo contribuições para o avanço científico, tecnológico, institucional e de ensino, tanto a nível teórico (revisão de literatura, "estado da arte", etc) quanto prático (resultados de pesquisa, relatos de trabalhos de aplicação prática, etc).

Obs: Por artigo divulgado de forma restrita entendese aquele divulgado em:

a) anais de congresso estrangeiro;

b) anais de congresso nacional mas apenas em forma resumida;

c) revista estrangeira de pouca penetração nacional. Os artigos serão submetidos a 3 membros do Conselho Científico da revista para avaliação. Os originais enviados, aprovados ou não aprovados, não serão devolvidos.

Normas para publicação, formato e padronização

\section{Envio do arquivo}

Enviar arquivo editado em Word for Windows para o endereço de e-mail da revista: pep@ufrgs.br ou pelo site www.ufrgs.br/pep

\section{Idioma}

O artigo pode ser em português, espanhol ou inglês.

Os artigos em português e espanhol devem conter um abstract em inglês, além do resumo.

Artigos em inglês devem conter resumo em português além do abstract.

\section{Formatação:}

Margens: 2,5 cm, letra: Times corpo 11; espaço entre linhas: simples. $\mathrm{O}$ artigo deve ter no máximo 20 laudas.

$\mathrm{O}$ arquivo deve apresentar, na $1^{\underline{a}}$ página: título do artigo, nome(s) do(s) autor(es), titulação mais elevada, instituição de origem, resumo de no máximo 150 palavras e 3 palavras-chave, abstract em inglês de no máximo 150 palavras e 3 keywords.

As palavras estrangeiras devem aparecer no texto $\mathrm{em}$ itálico (ex: buffer).

Em números decimais, usar vírgula $(2,5)$ ao invés de ponto (2.5).

As figuras devem ser de boa qualidade, inseridas no texto. As figuras serão impressas em preto e branco e tons de cinza. As legendas, abaixo das figuras, devem iniciar com a palavra Figura, o número respectivo em algarismo arábico

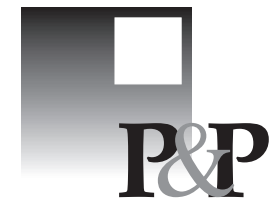

(as figuras são numeradas consecutivamente) e um traço (ex: Figura 1 - Diagrama de...)

As tabelas devem ser de boa qualidade, inseridas no texto. Devem ter legenda no topo, iniciando com a palavra Tabela, o número respectivo em algarismo arábico (as tabelas são numeradas consecutivamente) e um traço (ex: Tabela 1 - Distribuição de...)

Os gráficos devem ser feitos em preto e branco e tons de cinza.

O rodapé deve ser utilizado apenas para a colocação das referências dos apuds.

Junto com o artigo, deve ser enviado um arquivo com o nome de cada um dos autores e seu endereço para contato (correio normal + e-mail + telefone).

O conteúdo dos artigos, bem como a sua forma, é de inteira responsabilidade dos autores.

A bibliografia consultada ou citada deve estar de acordo com os modelos a seguir:

Artigo de anais

WILLMORE, L. Determinants of market structure: a brazilian case study. In: ENCONTRO BRASILEIRO DE ECONOMETRIA, 8., Brasília, 1986. Anais... Rio de Janeiro: Sociedade Brasileira de Econometria, $1986 \mathrm{v}$. 2, p. 12-18.

Citação em livro

CARVALHO, R. de Q. Capacitação tecnológica, revalorização do trabalho e educação. In: FERRETI, Celso João et al. (org.) Novas tecnologias, trabalho e educação: um debate multidisciplinar. Petrópolis: Vozes, 1994. p.15-22.

\section{Livro}

CHIAVENATO, I. Introdução a Teoria Geral da Administração. 4. ed. São Paulo: Makron Books, 1993. 243p.

\section{Artigo de periódico}

DIAMOND, W. J. Three dimensional models of extreme vertices designs for four component mixtures. Technometrics, v.9, n.3, p. 8-15, Aug. 1967.

Enviar os artigos para:

\section{Revista Produto \& Produção}

site: www.ufrgs.br/pep e-mail: pep@ufrgs.br

\section{Maiores informações: \\ Universidade Federal do Rio Grande do Sul - E. E. Programa de Pós-Graduação em Engenharia de Produção \\ Praça Árgentina, $n^{\circ} 9,2^{\circ}$ andar, sala LOPP \\ CEP 90040-020 / Porto Alegre - RS}

tel: (51) 3316-3948

fax: (51) 3316-4007

Contato: Cristine Brondani

Suporte técnico - Revista Produto\&Produção 